\title{
La hermenéutica simbólica de Ricoeur: de camino hacia la ética
}

\author{
The Symbolic Hermeneutics of Ricoeur: \\ On the Path Towards Ethics
}

A hermenêutica simbólica de Ricoeur: a caminho da ética

Dr. Eloy Sánchez Cárdenas*

\section{RESUMEN}

En el presente trabajo nos enfocaremos en las interpretaciones Palabras clave: de Paul Ricoeur en el marco de su hermenéutica simbólica, tehermenéutica, niendo en mente que ésta no está aislada, sino que es parte del camino que sigue dentro de su hermenéutica del sí, la cual no se símbolo, Ricoeur, ética. entendería sin su planteamiento ético, hacia el cual, consideramos, van encaminadas sus reflexiones acerca del símbolo. Para lograr lo anterior, en un primer momento, previa introducción breve, analizaremos lo que Ricoeur llama "injerto de hermenéutica en la fenomenología"; en un segundo momento abordaremos sus dos concepciones de la hermenéutica simbólica: hermenéutica de la escucha o amplificadora y hermenéutica de la sospecha o reductora; por último, señalaremos la importancia de la hermenéutica en el camino hacia su propuesta ética, sin ser esta última objeto de reflexión del presente trabajo.

\section{ABSTRACT}

In this work, we will focus on the interpretations of Paul Ricoeur Keywords: in the framework of his symbolic hermeneutics, considering hermeneutics, that it is not isolated, but rather a part of the path that continues within his hermeneutics of yes, which could not be understood symbol, Ricoeur, ethics. without his ethical proposal, towards which, we believe, his re-

* Mexicano. Licenciado en Filosofía; maestro y doctor en Humanidades: ética, por la Universidad Autónoma del Estado de México, México. Profesor investigador del Instituto de Estudios sobre la Universidad, de la Universidad Autónoma del Estado de México. Contacto: eloy_sanchez80@hotmail.com ORCID: https://orcid.org/0000-0002-2329-9637 
flections on the symbol are directed. To do this, after a brief introduction, we will analyze what Ricoeur calls the "graft of hermeneutics onto phenomenology." Then we will address his two conceptions of symbolic hermeneutics: hermeneutics of listening (amplification), and hermeneutics of suspicion (reduction). Finally, we will discuss the importance of hermeneutics in the path towards his ethical proposal, although this is not reflected upon in the present article.

\section{RESUMO}

No presente trabalho focaremos as interpretações de Paul Ri-

Palavras-chave: coeur no marco de sua hermenêutica simbólica, tendo em menhermenêutica, te que esta não está isolada, mas sim faz parte do caminho que símbolo, Ricoeur, segue dentro de sua hermenêutica do sim, a qual não seria comética. preendida sem sua abordagem ética, em direção à qual, consideramos, vão encaminhadas suas reflexões sobre o símbolo. Para conseguir o anterior, em um primeiro momento, após uma breve introdução, analisaremos o que Ricoeur chama de "enxerto de hermenêutica na fenomenologia". Em um segundo momento abordaremos suas duas concepções da hermenêutica simbólica: hermenêutica da escuta ou amplificadora e hermenêutica da suspeita ou redutora. E, por último, indicaremos a importância da hermenêutica no caminho em direção a sua proposta ética, sem ser esta última objeto de reflexão do presente trabalho. 


\section{Introducción}

El desarrollo del pensamiento filosófico de Paul Ricoeur (1913-2005) se llevó a cabo durante la segunda mitad del siglo XX, y se reconoce deudor de la fenomenología de Husserl, la filosofía reflexiva - de Descartes a Nabert- y la hermenéutica - como filosofía de Heidegger y Gadamer-. Retomando esta última, de acuerdo con Jean Grondín (1520), hay tres grandes concepciones de la hermenéutica: 1) en sentido clásico, como interpretación del sentido de los textos (jurídica, literaria y religiosa);2) en sentido metodológico, como reflexión metodológica sobre la pretensión de verdad y el estatuto científico de las ciencias del espíritu, presente en Dilthey, y 3) el sentido existencial en tanto filosofía universal de la interpretación. Desde esta división, la hermenéutica va desde la técnica de interpretar textos, pasando por la fundamentación de las ciencias del espíritu, a la interpretación de la existencia humana con un carácter ontológico. De esta última, principalmente, se reconoce deudor Paul Ricoeur, y si bien toma una postura crítica respecto de cada una de estas influencias, en realidad no las abandona.

Ahora bien, el mismo Ricoeur reconoce que su pensamiento está enmarcado en cuatro preguntas: ¿Quién habla? ¿Quién actúa? ¿Quién se narra? ¿Quién es el sujeto de imputación moral? (2006a 167). En la respuesta a esta última se encuentra, de forma explícita, su planteamiento ético, al que llama su "pequeña ética" (estudios 7 a 9 de Sí mismo como otro). Si bien el propósito del presente trabajo no es desarrollar la propuesta ética de Paul Ricoeur, sino establecer la relación entre ésta y la hermenéutica simbólica, aun así haremos algunos señalamientos muy generales sobre ella. En el estudio séptimo, recordando a Aristóteles, da su definición de ética: "intencionalidad de la vida buena, con y para el otro en instituciones justas" (Id. 176). Pero cuando la búsqueda de la vida buena se extravía, es necesaria la norma, para corregir; entonces recurre a Kant con su punto de vista deontológico, y cuando la aplicación de la norma se encuentra en conflicto, es necesario regresar al objetivo ético, que se da en el juicio moral en situación: la sabiduría práctica. Se pasa así de la atestación al reconocimiento y a la convicción. Todo lo anterior se refiere al sí mismo como otro, pero este sí mismo, para Ricoeur, comparte una identidad tripartita: 1) sí mismo como ídem: identidad como mismidad, identidad sustancialista; 2) sí mismo como identidad narrativa: identidad narrativa, tanto individual 
como comunitaria; 3) sí mismo como ipse: identidad como ipseidad, identidad ética. Es en esta última en la que somos seres plenamente éticos. Aquí se responde a la pregunta ¿quién es el sujeto de imputación moral? La identidad narrativa cumple la función de mediación entre la identidad ídem y la identidad ipse, es decir, se encuentra entre la descripción y la prescripción.

Para nuestro autor, el ser ético es una búsqueda, pero esta búsqueda empieza con la interpretación de los símbolos y sigue con la interpretación de los textos y de la acción como texto. En todo este recorrido ya hay elementos éticos. Como en el presente trabajo pretendemos mostrar los elementos éticos de la hermenéutica simbólica de Ricoeur, partimos de la idea que, en su estudio temático sobre la existencia humana, la hermenéutica simbólica es necesaria para llegar al planteamiento ético. Pero también la interpretación de los símbolos y de los mitos es necesaria para ser seres éticos en nuestra vida cotidiana.

Teniendo en cuenta las anteriores consideraciones, empezaremos señalando lo que Ricoeur llama "injerto de hermenéutica en la fenomenología", remarcando su propio camino y diferenciándolo del que había seguido Heidegger. Posteriormente, abordaremos las dos hermenéuticas de las que habla Ricoeur, con el propósito de resaltar los elementos éticos presentes en ellas. Por último, resaltaremos la relación entre la hermenéutica simbólica y la ética.

\section{El injerto de hermenéutica en la fenomenología}

En su Autobiografía intelectual, de 1995, Ricoeur señala que la elaboración de Finitud y culpabilidad, publicado en 1960, lo llevó a tomar dos decisiones: la primera, demostrar que el mal es una estructura contingente e histórica, por lo que elabora su ontología de la desproporción, la fragilidad humana; y la segunda, de orden metodológico, es caracterizada como un injerto de la hermenéutica en la fenomenología, y consiste en el desvío por los símbolos y los mitos para acceder a lo concreto de la mala voluntad, esto es, un rodeo en la reflexión. Así pues, cuestiona a Husserl y a Descartes en lo que se refiere a la inmediatez, la transparencia y la apodicticidad del cogito: "El sujeto, afirmé, no se conoce a sí mismo directamente, sino solo a través de los signos depositados en su memoria y su imaginario por las grandes culturas" (2007 
$32)^{1}$. Por esto mismo se resiste a utilizar el término "yo", y en su lugar utiliza el de "sí" (Ricoeur 2006a XXXII Y XXXIV)². También se abstiene de utilizar los términos "conciencia" y "sujeto" (Ricoeur 1993 99, 106), de ahí su hermenéutica del sí y no del yo, o del sujeto. Es esta resistencia ante el sujeto que se capta a sí mismo de forma inmediata lo que lleva a Ricoeur a hablar de la necesidad de la mediación, es decir, del rodeo de la reflexión, que se da en un primer momento a través de los símbolos (una hermenéutica simbólica), desarrollada en la segunda parte de Finitud y culpabilidad: la simbólica del mal. Es aquí, según recuerda en su Autobiografía intelectual, donde da su primera definición de "hermenéutica", "concebida como un desciframiento de los símbolos" (Ricoeur 2007 33). Pero también en su obra Freud: una interpretación de la cultura continúa con una hermenéutica simbólica. Considerando así que, como señala Juan Maciá Clavel, "la hermenéutica será entonces no una mera técnica de interpretación, sino una concepción de la vida del sujeto que se autocomprende mediatizadamente a través de los signos" (1998 34).

En un artículo titulado "Existencia y hermenéutica" del texto $E l$ conflicto de las interpretaciones. Ensayos de hermenéutica, Ricoeur habla precisamente del injerto de hermenéutica en la fenomenología, y dice que lo plantea de ese modo porque la hermenéutica se había desarrollado con anterioridad a la fenomenología en el campo de la exégesis desde Aristóteles, y en el campo de las ciencias históricas, principalmente con Schleiermacher y Dilthey. Indica que este injerto de la hermenéutica en la fenomenología se da por una vía corta seguida por Heidegger, quien plantea una ontología de la comprensión que, "al romper con los debates de método, se inscribe de entrada en el plano de una ontología del ser finito, y reconoce en él el comprender no ya como un modo de conocimiento, sino como un modo de ser" (Ricoeur 2003 11). La hermenéutica, en el sentido de Heidegger, se convierte en una analítica del Dasein, en la que la comprensión no tiene un carácter epistemológico, sino ontológico. Recordemos que la tarea principal de Ser y tiempo es plantear, de forma correcta, la pregunta por el sentido del ser, para lo que primero interrogará a un ente, que somos nosotros

Cf. (Ricoeur 1991 26-42).

Cf. (Ricoeur 2007 14, 32). 
mismos: "La filosofía es una ontología fenomenológica universal, que tiene su punto de partida en la hermenéutica del Dasein" (Heidegger 61). En este sentido, el autor de Ser y Tiempo realizará una interpretación directa del ser del Dasein. Si bien es una ontología de la comprensión, pues esta es vista, tanto por Ricoeur como por Heidegger, como un modo de ser y solo de forma derivada como modo de conocer, nuestro filósofo no coincidirá con el autor de Ser y Tiempo en lo que se refiere al modo de interpretación de la existencia humana.

Por eso, para Ricoeur, el injerto de la hermenéutica en la fenomenología se da también por otra vía que denomina "vía larga", y es la que se propone seguir, cuestionando la vía corta o, más bien, señalando que ésta

no nos ofrece ningún medio para demostrar en qué sentido la comprensión propiamente histórica se deriva de esta comprensión originaria. ¿No será mejor, de aquí en más, partir de las formas derivadas de la comprensión, y mostrar en ellas los signos de su derivación? (Ricoeur 2003 15).

En última instancia, lo que persigue Ricoeur con la vía larga es, lo mismo que Heidegger, una ontología de la comprensión, pues reconoce que la vía corta, la de Ser y Tiempo, se pronuncia en contra de un idealismo (principalmente el de Husserl que va desde Las investigaciones lógicas hasta el de las Meditaciones Cartesianas) que se mantiene dentro de las pretensiones de un conocimiento objetivo e inmerso en la dialéctica sujeto-objeto, resaltando que el último Husserl pone el énfasis en el "mundo de la vida", la Lebenswelt. No obstante, la ontología de Ricoeur será una ontología militante.

Ricoeur menciona que, con Heidegger, la verdad ya no es una cuestión de método, sino de manifestación del ser, por eso recurre al plano mismo en el que la comprensión se da: el lenguaje, para ir de las formas derivadas de la comprensión a la comprensión originaria (esta última afrontada de forma directa por Heidegger). "Toda comprensión óntica u ontológica se expresa, ante todo y desde siempre, en el lenguaje” (Ricoeur 2003 16), en el lenguaje es donde la comprensión se da, en este sentido la comprensión de sí tiene como mediación el lenguaje, la vía larga. Así como Ricoeur no estuvo de acuerdo con el Cogito cartesiano, que servía de fundamentación para todo el edificio del conocimien- 
to, con un carácter eminentemente epistemológico, tampoco estará de acuerdo con Heidegger en realizar una interpretación directa del Dasein, aunque ahora ésta sea de carácter ontológico. Y es el lenguaje simbólico el que, en un primer momento, sirve para lograr este propósito. Ahora bien, una hermenéutica simbólica hace ver que el lenguaje simbólico pide ser referido a la existencia, por eso Ricoeur afirma que "toda hermenéutica es, explícita o implícitamente, comprensión de sí por el desvío de la comprensión del otro" (Id. 16). De ahí que reafirme la necesidad del injerto de la hermenéutica en la fenomenología.

Cabe señalar que la hermenéutica simbólica lleva a una filosofía reflexiva, y esta, en Ricoeur, no plantea un cogito inmediato, sino uno que se capte en sus objetos, obras y actos. En última instancia, la hermenéutica simbólica y la filosofía reflexiva persiguen una ontología de la comprensión, pero no una ontología triunfante o una vía directa como Heidegger, sino una ontología militante; por eso nuestro filósofo termina el artículo "Existencia y hermenéutica" de la siguiente forma: "la ontología es la tierra prometida para una filosofía que comienza por el lenguaje y por la reflexión; pero, como Moisés, el sujeto que habla y reflexiona sólo puede percibirla antes de morir" (Id. 27). ${ }^{3}$ Esta es la ontología de la comprensión que persigue nuestro filósofo, una ontología militante, de ahí la necesidad de la mediación de los signos y los símbolos, es decir, de la hermenéutica simbólica, que es una parte del camino en su ontología de la comprensión de sí.

Teniendo en cuenta lo anterior, nuestro autor ve necesaria la interpretación de los símbolos para lograr una comprensión de nosotros mismos, es decir, el símbolo no sería algo accesorio o de lo cual se pudiera prescindir, mucho menos un momento evolutivo anterior a la ciencia, sino que es parte constitutiva de nuestro ser. De ahí que la interpretación del símbolo también sea un recorrido necesario para la comprensión del ser humano. La filosofía no puede partir de un punto cero, tal como pretendía Descartes. Cabe recordar que su propósito

Al final de otro artículo titulado "La cuestión del sujeto: el desafío de la semiología", contenido también en El conflicto de las interpretaciones, vuelve a insistir Ricoeur en la vía larga: "la apropiación de mi deseo de existir es imposible por la vía corta de la conciencia, sólo la vía larga de la interpretación de los signos está abierta. Tal es mi hipótesis de trabajo filosófico: lo llamo reflexión concreta, es decir, Cogito mediatizado por todo el universo de los signos" (Ricoeur 2003240 ). 
principal es la comprensión de sí, que no puede darse de forma inmediata. Jean Grondin recuerda que, para Ricoeur, en lo que se refiere al injerto de la hermenéutica en la fenomenología:

su motivo de fondo es que el ego no puede conocerse directamente, por introspección, sólo puede comprenderse por la vía indirecta de la interpretación de los grandes símbolos (adán y Eva, Job, el orfismo, etcétera), que intentan dar sentido al problema del mal (108).

La hermenéutica de sí, desarrollada en Sí mismo como otro, en la que Ricoeur plantea su pequeña ética, tiene su punto de partida en la hermenéutica simbólica, en la cual nos comprendemos a nosotros mismos por mediación de los símbolos, y forma parte del camino que lleva a su propuesta ética. Sobre la hermenéutica del sí Johann Michel plantea la conveniencia de volver a pensar la antropología de Ricoeur bajo la luz del concepto "cuidado de sí", del cual hablan tanto Heidegger como Foucault, aunque aclara que Ricoeur no hace mucho uso de dicho concepto. Si bien Johann Michel se está refiriendo principalmente al prólogo de Sí mismo como otro, en una nota a pie de página hace la siguiente aclaración: "en la filosofía del sujeto de Ricoeur, el concepto de sí mismo es central, en particular a través de la problemática de la hermenéutica de sí mismo. Como se verá la hermenéutica de sí es parienta de la propia noción de 'cuidado de sí"' (Michel $61)^{4}$. Estas observaciones de Michel nos confirman la idea de que, en Ricoeur, desde el principio hasta el final de su obra, hay una preocupación eminentemente ética, y que la hermenéutica simbólica está desarrollada por Ricoeur dentro del marco de una hermenéutica del sí. Esto no implica que la hermenéutica simbólica sea secundaria, sino más bien necesaria, pues no se podría lograr una hermenéutica de sí sin una hermenéutica simbólica.

\section{Las dos hermenéuticas}

Ricoeur habla de dos hermenéuticas respecto del símbolo: una hermenéutica de la escucha o amplificadora, y una hermenéutica de la sospecha o reductora. La primera la desarrolla en Finitud y culpabilidad y la segunda en Freud: una interpretación de la cultura. Tratare-

4 Johann Michel aclara, sin embargo, que en Ricoeur no se trata de un sujeto en el sentido sustancialista. 
mos de resaltar que en esta hermenéutica simbólica ya hay presentes elementos éticos que serán desarrollados en su planteamiento ético. Sobre este tema, Mariflor Aguilar Rivero, en su texto Confrontación, crítica y hermenéutica, comenta que lo que diferencia a la hermenéutica de la sospecha de la hermenéutica de la escucha es que esta última no parte de la crítica, sino de la fe, y que la fe

está puesta en la verdad del significado o del sentido que se muestra, la cual, aunque parcial (dado que oculta), no inspira sospecha o desconfianza, por lo cual se realiza en forma natural el tránsito hacia el segundo sentido al que apunta, guardando éste con el primero una relación analógica, de semejanza. Puesto que hay confianza, la semejanza no es temida (1998 56).

En cualquiera de las dos hermenéuticas se trata de interpretación del sentido, solo que la hermenéutica amplificadora o de la escucha descansa sobre la confianza, y la hermenéutica de la sospecha lo hace sobre la crítica. Ahora realizaremos algunas observaciones respecto a la primera y posteriormente continuaremos con la segunda.

\subsection{La hermenéutica de la escucha o amplificadora}

En su texto Finitud y culpabilidad, Ricoeur trata de vincular una empírica de la voluntad con una mítica concreta. Recordemos la actitud crítica que mantiene respecto de la inmediatez del cogito: el síno se puede captar de forma inmediata. El método que sigue en esta obra está regido por tres preguntas: “ $¿$ Por qué, en efecto, solo se puede hablar de las pasiones que afectan a la voluntad en el lenguaje cifrado de una mítica? ¿Cómo introducir esta mítica dentro de la reflexión filosófica? ¿Cómo retomar el discurso filosófico después de haberlo interrumpido con el mito?" (Ricoeur 2004 10). Cada pregunta marca una dirección en la obra. La primera, que se desarrolla en la primera parte, constituye su antropología filosófica centrada en la falibilidad, entendida como la debilidad constitutiva que hace que el mal sea posible. Desde aquí vemos que ya se puede hablar de una cierta capacidad de hacer el mal, aunque es más fundamental la capacidad para hacer el bien. Podemos señalar también que el concepto de "capacidad" de Ricoeur, muy marcado al final de su obra, se encuentra ya bosquejado aquí. La segunda pregunta se desarrolla en la segunda parte como simbólica del mal y se dirige a realizar una hermenéutica del símbolo: "la exegesis de estos 
símbolos es la que prepara la inserción de los mitos en el conocimiento que el hombre adquiere de sí mismo" (Id. 11). Se trata de introducir los mitos en el discurso filosófico, y aclara el autor que no es accidental una hermenéutica para acceder al sí, sino que es esencial, como ya lo hemos mencionado.

La tercera pregunta se desarrolla en "El símbolo da que pensar" y es el texto en torno al cual gira la obra, ya que indica cómo se puede pensar a partir del símbolo, esto es, cómo continuar el discurso filosófico una vez que se ha pasado por los símbolos y los mitos. Para Ricoeur, el mito no es algo falso, sino "un relato tradicional referido a acontecimientos ocurridos en el origen de los tiempos y destinado a fundar la acción ritual de los hombres de hoy y, de modo general, a instaurar todas las formas de acción y de pensamiento mediante las cuales el hombre se comprende a sí mismo dentro de su mundo" (Id. 170). Entonces, mediante el mito el hombre se comprende a sí mismo y es en el mito en donde se puede comprender al hombre en su totalidad, aunque nuestro autor limite su análisis a los mitos del comienzo y del fin del mal. Pero también los mitos influyen en la acción de las personas. Aclara Ricoeur que los mitos son símbolos en segundo grado o secundarios, como el mito de la caída, los símbolos primarios son los de la confesión: culpa, pecado y mancilla, y los símbolos de tercer grado son los de la especulación. Por eso el mito sirve como intermediario entre la reflexión sobre el mal y la experiencia viva del mal. Habrá que precisar, aquello que permite un análisis de los símbolos primarios y del mito es que ambos son lenguaje: el de los símbolos primarios es el lenguaje de la confesión y el mito es el relato. Aquí vemos la estrecha relación entre lenguaje, interpretación y comprensión, de ahí que sea posible tanto una hermenéutica de los símbolos como de los mitos. Es necesario mencionar que el paso por la hermenéutica en la filosofía de Ricoeur, específicamente en Finitud y culpabilidad, tiene como antecedente su renuncia a la eidética de Husserl, tal como lo menciona Jesús Conill en su texto Ética hermenéutica: "Ya no basta una eidética fenomenológica, sino que es preciso recurrir al lenguaje en el que se ha expresado la experiencia del mal: al lenguaje mítico y simbólico" (214). Señalamientos similares realiza Domenico Jervolino (246).

Es conveniente remarcar que esta hermenéutica simbólica (y también la que desarrolla en Freud: una interpretación de la cultura) ya es 
parte de la hermenéutica de sí, pues en los mitos y en los símbolos el hombre se comprende a sí mismo: "la conciencia de sí parece constituirse en su intensidad por medio del simbolismo, y sólo elabora una lengua abstracta en segunda instancia, por medio de una hermenéutica espontanea de sus símbolos primarios" (Ricoeur 2004 174). En esto vemos que la mediación que propone Ricoeur en su filosofía reflexiva, es decir, en el rodeo a través de los símbolos, tiene su fundamento en nosotros mismos, pues los símbolos sirven para comprendernos en nuestra propia existencia. Es decir, no podemos desarrollar una conciencia de nosotros mismos de forma directa, esto es, sin la mediación de los símbolos.

Ahora bien, con el lenguaje de la confesión tienen lugar los símbolos primarios, que después son elaborados en un relato por el mito y llevados a la reflexión por la especulación: "este lenguaje de la confesión es la contrapartida del triple carácter de la experiencia que saca a la luz: ceguera, equivocidad, escándalo" (Id. 172). No es propiamente la experiencia viva lo que se interpreta, sino el lenguaje en el que se expresa la experiencia. La experiencia viva tiene tres características: 1) es ciega porque permanece atrapada en la emoción, y la confesión, por medio de la palabra, la saca a la luz; 2) es equívoca, porque tiene varias capas o sentidos. En primer lugar, se encuentra la culpa que remite al pecado y éste a la mancha. La culpa es la indignación consigo mismo, el pecado pone al hombre ante Dios y la mancilla, es la mancha que infecta desde fuera. 3) Es escandalosa porque mueve a la interrogación:

... el pecado me torna incomprensible a mis propios ojos; Dios está oculto; el curso de las cosas ya no tiene sentido. En la línea de esta interrogación y para responder al no-sentido acechante, el mito relata "como empezó todo eso» y la gnosis elabora la famosa pregunta: póten ta Kaká; - ¿de dónde proceden los males?- y moviliza todos los recursos de su explicación" (Id. 173).

Esto último lleva a pensar en la mediación que ejercen los mitos para la comprensión de nosotros mismos, pues la experiencia viva del mal nos vuelve incomprensibles, lo que incita a preguntarnos y, a partir de esto, intentar comprendernos. El lenguaje simbólico de la confesión emerge en diferentes zonas o, dicho de otro modo, el símbolo tiene distintas dimensiones: cósmica, onírica y poética. En la dimensión cósmica el hombre lee lo sagrado en algunos aspectos del 
mundo, por ejemplo, el cielo o el sol. En la dimensión onírica se da el paso de la función cósmica a la función psíquica. Es con relación a esto que "Cosmos y Psique son los dos polos de la misma «expresividad»; me expreso al expresar el mundo; exploro mi propia sacralidad al descifrar la del mundo" (Id. 178)." Tanto la función cósmica como la onírica se complementan. La dimensión poética del mito es la que está más cerca del verbo: el lenguaje. Por eso Ricoeur diferencia la imagen poética de la imagen-representación, ésta hace presente la cosa ausente y aquella es algo nuevo. En esto parece coincidir con Gadamer, para quien también la imagen de la pintura y la imagen poética llevan a un "incremento de ser" (189). El lenguaje de la confesión es, entonces, un lenguaje simbólico. Después de que Ricoeur señala las tres dimensiones del símbolo: cósmica, onírica y poética, procede a lo que denomina "aproximaciones más concretas a la esencia del símbolo” (Ricoeur 2004 179).

En primer lugar, el símbolo es signo, comunica un sentido de los elementos del universo, del sueño o de la imagen poética. En segundo término, especifica que no todo signo es símbolo y dice que éste "oculta en su aspiración una intencionalidad doble" (Id. 180), un sentido literal, y que apunta más allá de sí mismo: la mancha es el sentido literal que apunta a la mancilla. Esta es la región del símbolo: el doble sentido. En tercer lugar, el símbolo se diferencia de la analogía en que ésta se considera desde fuera, el símbolo surge y se da en el sentido literal, no es una comparación, sino una donación: el símbolo da (en esto encontramos una relación con la última parte del texto "el símbolo da que pensar"). En cuarto lugar, se diferencia de la alegoría porque ésta es más interpretación, una hermenéutica, traducción, mientras que el símbolo es una creación espontanea, en otras palabras, uno da y la otra traduce. En quinto lugar, el símbolo se diferencia del símbolo usado en lógica formal, lo que explica remitiéndose a la estructura de la significación, que tiene una función de ausencia y una de presencia, la primera corresponde al símbolo utilizado en lógica, y la segunda al símbolo en el sentido de donación. Aquí la presencia se refiere a significar el mundo. En sexto lugar, especifica la diferencia entre símbolo y mito. Respecto al primero da la siguiente definición: "las significaciones analógicas espontáneamente formadas e inmediatamente donantes de sentido, así, la mancilla como análoga de la mancha (...) el sentido del agua como amenaza y como renovación en el diluvio y en el bautismo" (Id. 183). Define tam- 
bién "mito" (que tal vez también sea primitiva) como: "símbolo desarrollado en forma de relato, y articulado en un tiempo y en un espacio que no se pueden coordinar con los de la historia y de la geografía, según el método crítico" (Ibíd.). Recordemos que, con anterioridad, ya había presentado una definición de "mito", lo que no significa que se contradigan, sino que más bien se refuerzan, pues en la primera habla del mito como mediación para la comprensión de sí (Ricoeur 2004 170) y ahora resalta la distinción entre el mito y el procedimiento científico.

En el texto Teoría de la interpretación: discurso y excedente de sentido, en el tercer ensayo "La metáfora y el símbolo", Ricoeur retoma el problema del símbolo y lo compara con la metáfora - no ya con el mito-, y resalta que el símbolo tiene un momento semántico y uno no semántico, el momento no semántico es el que lo diferencia de la metáfora, que también tiene un doble sentido: uno literal y otro figurativo. Cuando el autor habla del momento no semántico del símbolo, indica por qué éste no puede convertirse en metáfora, el primero se da en el logos y la segunda en la oración, pero "el símbolo duda entre la línea divisoria del bios y el logos. Da testimonio del modo primordial en que se enraíza el discurso en la vida. Nace donde la fuerza y la forma coinciden" (Ricoeur 2006b 71) ${ }^{5}$. Por una parte, la metáfora es una creación libre y, por otra, el símbolo está arraigado en el cosmos o la vida. Es decir, el símbolo no está separado de la existencia humana o, visto de otra forma, la existencia humana tiene a los símbolos como constitutivos de su ser. Así pues, toda interpretación del ser humano que no tome en consideración los símbolos será una interpretación incompleta. Ricoeur concluye el tercer ensayo diciendo que, por una parte, hay más en la metáfora que en el símbolo, pues la primera trae al lenguaje lo que en el segundo estaba implícito; pero, por otra parte, hay más en el símbolo que en la metáfora, porque "los símbolos tienen raíces" (Id. 82), esto es aquello que había llamado la parte no semántica del símbolo. Esto quiere decir que los símbolos están enraizados en la existencia humana.

\footnotetext{
5 Es necesario aclarar que, para Ricoeur, el símbolo significa más que la literalidad: tiene un excedente de sentido. Para aquel que participa del símbolo, no hay una oposición entre excedente de sentido y sentido literal. Pero para otra interpretación del símbolo "es el reconocimiento del sentido literal lo que nos permite ver que un símbolo contiene más sentido. Este excedente de sentido es el residuo de la interpretación literal" (2006b 68).
} 
Voy a retomar uno de los símbolos que Ricoeur estudia en Finitud y culpabilidad: la mancilla, con el propósito de resaltar su preocupación por el aspecto ético. La mancilla es un acto que desencadena un mal, un acto impuro. Pero la impureza no está medida en la mancilla por "la imputación a un agente responsable, sino por la violación objetiva de una prohibición" (Ricoeur 2004 191). Antes de esto, Ricoeur había señalado que, con la mancilla, entramos en el reino del terror. Las prohibiciones están más referidas a acontecimientos del mundo que a intenciones de un agente, de ahí que para la mancilla no haya distinción entre lo físico (mal-estar) y lo ético (mal-hacer). El autor señala la mancilla primordial de la sexualidad, que tiene un carácter pre-ético, pero que también está determinada por la prohibición que dice quién ha cometido una impureza, un mal. No obstante, aquí no se forma una verdadera ética, sino que se forma en el trabajo, la apropiación, la política. Es precisamente aquí donde se forma una ética de la relación con el otro, de la justicia y del amor. Vemos una preferencia de lo ético sobre la norma, como lo planteará posteriormente en su "pequeña ética".

Ricoeur apunta a que "el hombre entra en el mundo ético por el miedo y no por el amor" (Id. 193), es lo que llama el "terror ético". Ahora bien, el mundo de la mancilla es previo a la separación entre lo ético y lo físico; lo primero está mezclado con el sufrimiento físico y lo segundo con significaciones éticas: si sufres has pecado. La separación entre lo ético del pecado (mal obrar) y lo físico del sufrimiento (mal padecer) se da con la figura del "justo doliente", Job, pues sufre sin haber cometido ningún pecado. Nuestro autor aclara que la mancilla no es una mancha como tal, sino que es una mancha simbólica; para que se hable de "mancilla" debe haber ley, más precisamente prohibición. La mancilla entra al mundo del habla por la prohibición, pero también por la confesión, el temor dicho: la expulsión mediante la palabra del mal. La confesión, a diferencia de la prohibición, tiende más a lo ético que a lo físico, y esta aspiración tiene tres grados: 1) el primero se refiere a la exigencia de castigo justo. 2) El segundo, además del sufrimiento justo, espera que el castigo tenga un fin: restablecer el orden. 3) El tercero, además de los anteriores, abarca la esperanza de que el temor desaparezca de la vida de la conciencia: "Solo el amor perfecto destierra el temor (...) la mancha es el «esquema» primero del mal" (Id. 208). 
Vemos en esto un señalamiento constante de Ricoeur a lo largo de toda su obra: la originalidad de la bondad y de la justicia sobre el mal, como en el diálogo que mantiene a finales de la década de los 90 con el neurobiólogo Jean-Pierre Changeux, en el que remarca, comentando a Kant, que por muy radical que sea el mal, la bondad es más originaria, e inmediatamente dice: "en cuanto a la prevalencia, en el fondo de la reflexión, del destino fundamental a la bondad y la justicia, diría yo que es lo que preside el proyecto de mejoramiento de la especie humana" (Ricoeur y Changeux 287). Este sería el papel de la ética: colocar en primer lugar y como meta última la bondad, y no la maldad.

Así, por una parte, se da preferencia al bien sobre la norma y, por otra, a la bondad sobre la maldad. Entonces la prohibición pasa a un segundo término y el amor a un primero. Ya desde el estudio que realiza del símbolo vemos una separación entre lo prohibitivo, la norma, y la moral y la ética con su tendencia al bien, en la que ésta cobra primacía sobre la primera, lo que será resaltado en su pequeña ética, cuando da, precisamente, su definición de ética: "llamemos «intencionalidad ética» a la intencionalidad de la «vida buena» con y para el otro en instituciones justas" (Ricoeur 2006a 176). Resalta que la intencionalidad ética tiene primacía sobre la moral y, cuando ésta entra en conflicto, se debe recurrir de nueva cuenta al objetivo ético. Posterior a La simbólica del mal, en el capítulo II del libro primero del texto Freud: una interpretación de la cultura, después de hablar de las dos definiciones de interpretación: una demasiado larga (que se remonta a Aristóteles) y otra demasiado corta (que se refiere principalmente a la exegesis de los textos), Ricoeur plantea que no hay una hermenéutica general, sino teorías separadas. Él pretende centrarse en los polos opuestos de las hermenéuticas. Por un lado está la hermenéutica como restauración de sentido, que desarrolló en La simbólica del mal y hemos venido comentando, y, por otro, como desmitificación. Continuaremos ahora con la segunda hermenéutica respecto del símbolo.

\subsection{La hermenéutica de la sospecha o reductora}

$\mathrm{Al}$ inicio de su texto sobre Freud, Ricoeur indica que todas las indagaciones filosóficas coinciden en el lenguaje, lo que se ha llamado el "giro lingüístico". El psicoanálisis entra en este debate por la obra de Freud, 
de la que le interesa principalmente la nueva comprensión del hombre que introduce. Retoma de Freud La interpretación de los sueños, e indica que ésta entra en el debate sobre el lenguaje no solo por su interpretación de la cultura, sino porque hace del sueño el modelo de las manifestaciones disfrazadas del deseo. Lo que se encuentra sujeto a interpretación no es el sueño, sino el lenguaje en el que se expresa, el texto con el que se relata el sueño. Lo que da derecho al psicoanálisis a participar en el debate sobre el lenguaje es lo que quiere decir el hombre deseante. A partir del sueño se habla de una semántica del deseo, y es aquí donde aporta una definición de símbolo:

... el sueño y sus análogos se inscriben así en una región del lenguaje que se anuncia como lugar de significaciones complejas, donde otro sentido se da y se oculta a la vez en un sentido inmediato; llamaremos símbolo a esa región del doble sentido (Ricoeur 2009b 10).

La hermenéutica de la simbólica del mal es una interpretación del doble sentido, principalmente del que se da. No debemos perder de vista que de lo que se trata en el fondo es de la comprensión de sí, es decir, de ver qué aporta la hermenéutica simbólica a una mejor comprensión de nosotros mismos, de nuestro ser. Este rodeo no es una pérdida de tiempo, sino un enriquecimiento de la comprensión del ser del hombre. Cabe aclarar que nuestro filósofo hace una distinción entre: 1) símbolo en psicoanálisis, en el que se ve como disimulación del deseo o lenguaje distorsionado; y 2) símbolo en fenomenología de la religión, en la que se ve como revelación de lo sagrado. Indica Ricoeur que la hermenéutica es "la teoría de las reglas que presiden una exégesis, es decir, la interpretación de un texto singular o de un conjunto de signos susceptible de ser considerado como un texto" (Id. 11). Es así como, mediante la interpretación del doble sentido, realizada por la hermenéutica, el símbolo entra en el ámbito de la filosofía del lenguaje. También establece una relación entre símbolo e interpretación: por una parte, el símbolo necesita ser interpretado; por otra, la interpretación tiene como objeto las expresiones de doble sentido. Pero aclara que hay dos posibles interpretaciones del símbolo: como desenmascaramiento y como restauración del sentido. Lo que se traduce, a su vez, en una hermenéutica de la sospecha y una hermenéutica de la confianza. En este sentido, plantea también que su definición de "símbolo" 
se encuentra entre otras dos: a) una demasiado amplia, denominada "función simbólica”, en la que se ve al símbolo como mediador entre nosotros y la realidad, sustentada por Cassirer. Esta sirve tanto para percibir como para decir, abarcando así todas las expresiones de la cultura. En esta definición de símbolo hay puntos en los que se muestra formas elaboradas como la literatura, la filosofía, la moral y la religión, y otras formas menos elaboradas, como los mitos y ritos, lo onírico y la imaginación poética. Por otra parte, b) una interpretación demasiado estrecha, que caracteriza el nexo de sentido a sentido por la analogía. Por último, Ricoeur propone delimitar el símbolo de acuerdo con la interpretación, es decir, hay símbolo en donde una expresión lingüística se presta a interpretación por su doble sentido. Lo que hace necesaria la interpretación es la

estructura intencional que no consiste en la relación del sentido con la cosa, sino en una arquitectura del sentido, en una relación de sentido a sentido, del sentido segundo con el primero, sea o no una relación de analogía, sea que el sentido primero disimule o revele el segundo (Id.20).

Así pues, la interpretación pertenece al símbolo y el símbolo propicia la interpretación, hay una relación de interdependencia. La interpretación como ejercicio de la sospecha se refiere principalmente a lo que llama la "escuela de la sospecha", en la cual ubica a Freud, Marx y Nietzsche, pues los tres consideran a la conciencia como falsa, pero (y Ricoeur resalta esto) con el propósito de llegar a una palabra más auténtica; y menciona que "a partir de ellos, la comprensión es una hermenéutica: buscar el sentido, en lo sucesivo, ya no es deletrear la conciencia del sentido, sino descifrar sus expresiones" (Id. 33). No se trata, entonces, de destruir, sino solo de liberar de las ilusiones de la conciencia. Javier Bengoa Ruiz de Azúa señala que, para Ricoeur:

el rasgo común que une a estos autores es haber puesto en duda la certeza inmediata de la conciencia y haber desarrollado una hermenéutica que reduce las ideologías, la moral y la cultura en general a una expresión de la alienación económica, de la economía de poder o de la economía pulsional (86).

Ricoeur resalta que, en realidad, los maestros de la sospecha no pudieron escapar a la filosofía de la conciencia; de ahí la necesidad de no 
quedarse en la hermenéutica como sospecha, siendo esta un momento necesario en la interpretación de símbolo para la interpretación de nosotros mismos. Al tratar el tema de la hermenéutica de la sospecha y de la escucha, Maceiras y Trebolle señalan que "ambas coinciden en reconocer la conciencia como lugar de llegada, aquello de donde no debemos partir. La conciencia no es abolida, pero tampoco es realidad primera. Ella no es ya dato inicial, sino resultado de una tarea continuada" (130). En este sentido, Ricoeur recupera ambas hermenéuticas para lograr una comprensión de nosotros mismos mediatizada por los símbolos, y se pregunta si no le faltará a esta escuela de la sospecha "la gracia de la Imaginación” (2009b 35). Recordemos que en Finitud y culpabilidad apela a la imaginación sobre el reino de los fines de Kant, es decir, a un momento de bondad, libre de maldad, y aquí relaciona con la palabra como revelación. Esto lleva a pensar en una hermenéutica que se libere de las ilusiones de la conciencia, pero también que presuponga una utopía alcanzable de bondad. Recordemos la intencionalidad de la vida buena y lo que "preside el proyecto de mejoramiento de la especie humana". Es aquí en donde se apunta hacia la ética, es decir, a no quedarse solo en la hermenéutica simbólica.

\section{De la hermenéutica a la ética}

La cuestión que preocupa a Ricoeur es cómo pasar de una hermenéutica simbólica a una filosofía de la reflexión, de ahí su idea que el símbolo es aquello que "da que pensar": busca ver cómo se enriquece la reflexión una vez que se ha pasado por la interpretación de los símbolos y los mitos, en relación con la filosofía reflexiva. Por una parte, hay una apelación del símbolo a la reflexión, pero, por otra parte, la reflexión tiene que acudir al símbolo.

En el texto Freud una interpretación de la cultura, Ricoeur dice que la apelación del símbolo a la reflexión se basa principalmente en tres rasgos del símbolo: 1) su estructura semántica; 2) la especulación de los mitos de principio y fin del mal; 3) todo símbolo pertenece a una totalidad significante. En el primer aspecto retoma la parte final de Finitud y culpabilidad: el símbolo da qué pensar (reconoce haber retomado el término de la crítica del juicio de Kant), crea el deber de pensar. Es conveniente resaltar la idea que considera el símbolo "como un índice de la situación del hombre en el corazón del ser en el que se 
mueve, existe y quiere" (Ricoeur 2004 489). Esto lleva a plantear una segunda revolución copernicana: "el símbolo hace pensar que el Cogito está en el interior del ser y no al contrario" (Ibíd). Esto implicaría, por una parte, que se debe partir de presupuestos del lenguaje - símbolos, mitos- para la interpretación de nosotros mismos, pues no se puede hacer filosofía partiendo de la nada. Por otra, el Cogito está en el ser y no el ser en el Cogito, nuestro ser no se puede reducir a una conciencia pura o a un sujeto abstracto. En el segundo aspecto los mitos, además del valor expresivo, tienen un valor heurístico, "ya que confieren universalidad, temporalidad y alcance ontológico a la comprensión de nosotros mismos" (Ricoeur 2009b 37). La comprensión de nosotros mismos se ve enriquecida por la interpretación de los mitos y los símbolos. En el tercer aspecto remite a la simbólica del mal, en la que ésta es solo una parte del simbolismo religioso y lo que le da realmente sentido es la simbólica de la salvación, es decir, un estado de pureza que le confiere al mal su verdadero sentido. Lo más importante es, entonces, considerar la totalidad del simbolismo, y esto es lo que pide ser llevado a reflexión. La interpretación sobre el mal tiene como fin mostrar que la bondad o la pureza son realmente el fundamento. Este planteamiento es el que mantendrá en Sí mismo como otro en su "pequeña ética" (estudios 7-9), al resaltar que el objetivo ético tiene primacía sobre la norma, y que cuando ésta, en su aplicación, entra en conflicto, se debe recurrir al objetivo ético.

En el apartado "El recurso de la reflexión al símbolo", Ricoeur se pregunta qué significa el Sí mismo de la reflexión, y remite al cogito ergo sum de Descartes, existir como ser pensante, en el que "la posición del sí es una verdad que se asienta por sí misma" (Id. 41). Pero ésta no se puede verificar como un hecho ni deducirse, simplemente se asienta en la reflexión. Además, el saber sobre este Sí mismo de la reflexión es abstracto y vacío. La filosofía de Ricoeur no se fundamenta en esta noción de sí mismo de la reflexión que se da de forma inmediata, por lo que no acepta que su filosofía sea denominada como una filosofía de la conciencia, si por esta se entiende conciencia inmediata de sí mismo. Es precisamente esa noción de "conciencia" la que critica constantemente. Nuestro autor no está en contra del Yo, sino solo de un Yo abstracto, por eso para él "la reflexión es el esfuerzo por volver a captar el Ego del Ego Cogito en el espejo de sus objetos, de sus obras y finalmente de sus actos" (Id. 41). En este sentido, 
vemos de nueva cuenta que la filosofía reflexiva es una hermenéutica del sí.

Se trata de captar el sí mismo de la reflexión, no de forma inmediata, lo que sería abstracto y vacío, sino por mediación, para lo que se requiere una interpretación, es decir, una hermenéutica. Por ello, Ricoeur comienza por una hermenéutica simbólica, después pasa a una hermenéutica de la acción, luego a una hermenéutica textual para, posteriormente, llegar a su propuesta ética. La reflexión no es intuición, es la vía larga, el rodeo. En esta vía larga la hermenéutica simbólica está en camino para llegar a un planteamiento ético. En este sentido, se distancia también de la concepción de la reflexión como una crítica que tuviera como propósito principal desarrollar una epistemología, tal como lo hizo Kant, y por ello pone el acento en la reflexión como "reapropiación de nuestro esfuerzo por existir" (Id. 42). De ahí que, más adelante, se pregunte si no será una limitación haber puesto el acento de la reflexión en el aspecto ético, pero su respuesta es no.

Así, pues, su filosofía reflexiva no se asienta en un Yo abstracto, ni tampoco en una justificación de lo que sea la ciencia, es decir, no es ni metafísica ni epistemología, sino más bien tiene como eje central la cuestión ética: del sí mismo "reapropiándose de su esfuerzo por existir". En donde, por cierto, retoma a Jean Nabert, y también a Spinoza, para apartarse de una ética como crítica de la moral al estilo de Kant. Así, para Ricoeur, "la reflexión es la apropiación de nuestro esfuerzo por existir y de nuestro deseo de ser, a través de las obras que atestiguan ese esfuerzo y ese deseo" (Id. 44). ${ }^{6}$ Aquí la reflexión reclama la interpretación, es decir, la filosofía reflexiva se convierte en hermenéutica, porque las obras requieren ser interpretadas, puesto que las obras son lenguaje, lenguaje simbólico. Por eso el símbolo reclama la interpretación y, a su vez, la reflexión reclama el símbolo para no tener un Yo vacío y abstracto.

La filosofía reflexiva no se entiende sin la hermenéutica y pasa a ser una hermenéutica del sí, es decir, busca llegar a una comprensión del

6 En otro artículo titulado "La cuestión del sujeto: el desafío de la semiología", ubica el psicoanálisis dentro de la hermenéutica y establece un vínculo entre el psicoanálisis y su filosofía reflexiva: "pasando por una hermenéutica la filosofía reflexiva sale de la abstracción; la afirmación de ser, el deseo y el esfuerzo de existir que me constituyen hayan en la interpretación de los signos la vía larga de la toma de conciencia" (Ricoeur 2003 239). 
sí, y no solo una intuición. Se constata aquí que el problema ético, ya desde la hermenéutica simbólica, adquiere una importancia central en la obra de Ricoeur, porque la comprensión de nosotros mismos no se da de forma inmediata, en palabras de François Dosse: "el símbolo le sirve entonces para romper la seducción perniciosa del estado narcisista de la conciencia de sí para quebrar al cogito en su establecimiento de sí mismo" (307).

En un artículo titulado "Psicoanálisis y hermenéutica", Ricoeur alude a la autonomía de esta última, indicando que la relación entre ambas se plantea a partir de la imposibilidad de considerar al primero como una ciencia de observación, por lo que propone revisar el estatuto epistemológico del psicoanálisis. En el primer apartado menciona los criterios de lo que es un hecho en psicoanálisis: 1) la experiencia capaz de ser dicha; 2) el deseo es dirigido a otro; 3) las manifestaciones del inconsciente o realidad psíquica; 4) lo relatado. En el segundo habla del psicoanálisis como una hermenéutica, señala la familiaridad del primero con las ciencias del texto y plantea que se "puede hablar de la psique como un texto por descifrar" (Ricoeur 2009a 68). En el tercer apartado indica los límites de una reformulación hermenéutica del psicoanálisis y, al final, menciona sus aportes a la primera: 1) "sólo se comprende uno a sí mismo a través de una red de signos, discursos y textos que constituyen la mediación simbólica de la reflexión" (Id.77). Se plantea aquí una crítica al cogito cartesiano y se resalta la importancia de la mediación; 2) "esta comprensión indirecta comienza por la incomprensión" (Ibíd.). Significa que la hermenéutica de la recolección necesita de la hermenéutica de la sospecha; 3 ) "la comprensión de sí debe pasar por un desprendimiento de sí” (Ibíd). Finaliza el artículo diciendo que, para Sócrates, "mentirosa es la vida que se sustrae al examen", resaltando la importancia de la sospecha, de la incomprensión hacia nosotros mismo. Curiosamente, en otro artículo titulado "La vida, un relato en busca de narrador” (2009a 192, 203)7, Ricoeur recurre nuevamente a Sócrates, resaltando el lugar que tiene la ética en su obra. Recordemos que, según Platón, Sócrates dice al final de su juicio, antes de su condena a muerte, que "una vida sin examen no tiene ob-

Si bien esto lo hace en el ámbito de los textos y no en el de los símbolos, el objetivo es el mismo: examinarnos a nosotros mismos, ya sea mediante el símbolo o mediante la literatura, el relato. 
jeto vivirla para el hombre" (Platón 38a 6-7), señalando que, "el mayor bien para el hombre es precisamente éste, tener conversaciones cada día acerca de la virtud" (Id.38a 2-4). Es decir, la pregunta sobre cómo vivir es la pregunta fundamental, así como la preocupación por la ética es la inquietud fundamental en Ricoeur.

\section{Conclusiones}

Diremos que, para Ricoeur, la hermenéutica simbólica marca el inicio de lo que llama el "injerto de hermenéutica en la fenomenología", o la vía larga de la interpretación de nosotros mismos - su ontología militante-, por oposición a la vía corta llevada a cabo por Heidegger en su analítica existencial. Tanto en la hermenéutica de la escucha como en la hermenéutica de la sospecha resaltan aspectos éticos en la interpretación del símbolo. En el primer caso, el símbolo tiene un influjo en la acción humana, se relaciona con la experiencia viva en lo cosmológico, en lo onírico y en lo poético. Es decir, se vincula con la existencia humana, pues los símbolos y los mitos son constitutivos de ella. En el caso específico de la mancilla, vemos ya la preferencia de lo ético sobre la norma, pues en la norma prohibitiva no se forma realmente una ética, y la mancilla, en tanto confesión, tiende más a lo ético como exigencia de castigo justo, restablecimiento del orden y elección del amor en lugar del temor. Desde este punto, ya Ricoeur piensa la bondad y la justicia como elementos más originarios que el mal. En el segundo caso, la hermenéutica de la sospecha, señalando que, a los maestros de la sospecha les faltaba la propuesta de un mundo de bondad, una utopía alcanzable, pues liberarnos de las ilusiones de la conciencia es necesario pero no suficiente, es más importante la búsqueda de la vida buena.

Lo anterior aplica no solo al tratamiento temático de los símbolos, sino también al de nuestra propia existencia, es decir, la aspiración a una vida de bondad y justicia es más fundamental y originaria que el mal, que existe en abundancia. ¿Quién podría decir que la injusticia es preferible a la justicia o que el mal es preferible a la bondad? En los símbolos y en los mitos es posible encontrar una interpretación del mal en el mundo, pero también una aspiración a la bondad y a la justicia. Los símbolos y los mitos forman parte de nuestra identidad como ídem porque son parte de nuestro pasado, de nuestra tradición, y tie- 
nen y han tenido un influjo en nuestra vida individual y comunitaria. Esa identidad como ídem a nivel individual y comunitario no puede ser extirpada o dejada de lado, sino que se debe asumir como parte de nuestra existencia, de nuestra identidad. No obstante, en el pensamiento de Ricoeur, no solo estamos constituidos por la identidad ídem - una identidad sustancialista-, sino que debemos pasar a una identidad como ipse, es decir, a una vida ética, incorporando los símbolos y mitos por mediación de la identidad narrativa.

La ciencia, en la actualidad, pretende ser la solución a los problemas de contaminación ambiental, violencia, administración de las sociedades, salud, educación; pero la ciencia no es todo ni lo puede todo: ¿por qué no regresar a la interpretación de nosotros mismos, como personas y comunidades, a través de los símbolos y los mitos en busca de una vida ética? Aquí radicaría la importancia de la hermenéutica simbólica de Ricoeur. Tal vez así podríamos llegar a vivir realmente "con y para el otro en instituciones justas", en respeto a la norma, recurriendo al objetivo ético en situaciones de conflicto. Lo mismo se podría aplicar a las filosofías que postulan un sujeto abstracto o que parten de cero sin tener nada que les anteceda; una conciencia que se capta a sí misma pensando: un sujeto solipsista o narcisista.

Tanto la hermenéutica de la confianza como la de la sospecha abonan a la comprensión de nosotros mismos. La reflexión necesita de la interpretación de los símbolos, no se puede hacer filosofía partiendo de cero, puesto que ya hay algo que nos antecede. Y la hermenéutica del sí es esencialmente reflexión sobre nuestro ser. La hermenéutica simbólica es parte de la hermenéutica del sí, es una parada necesaria en el camino hacia la interpretación de nuestro ser ético. Entonces, la ética es el tema fundamental en el pensamiento de Ricoeur. En el lenguaje simbólico podemos comprendernos a nosotros mismos, pero este no agota esa comprensión, porque la hermenéutica simbólica forma parte del camino de la hermenéutica del sí, y como tal, es indispensable para un planteamiento ético.

\section{Bibliografía}

Aguilar Rivero, Mariflor. Confrontación, crítica y hermenéutica. Gadamer, Ricoeur, Habermas. México: UNAM y Fontamara, 1998. 
Bengoa Ruiz de Azúa, Javier. De Heidegger a Habermas. Hermenéutica y fundamentación última en la filosofía contemporánea. Barcelona: Herder, 2002.

Conill Sancho, Jesús. Ética hermenéutica. Madrid: Tecnos, 2010.

Dosse, François. Paul Ricoeur. Los sentidos de una vida (1913-2005). Traductor Pablo Corona. Buenos Aires: Fondo de Cultura Económica, 2013.

Gadamer, Hans-Georg. Verdad y método. Traductores Ana Agud Aparicio y Rafael Agapito. Salamanca: Sígueme, 2005.

Grondin, Jean. ¿Qué es la hermenéutica? Traductor Antoni Martínez Riu. Barcelona: Herder, 2008.

Heidegger, Martin. Ser y Tiempo. Traductor Jorge Eduardo Rivera. Santiago de Chile: Editorial Universitaria, 2005.

Jervolino, Domenico. "La unidad de la obra de Ricoeur: L'homme capable". Hermenéutica Intercultural, Revista de Filosofía 14 (2005): 243-260.

Maceiras Fafian, M. y Trebolle Barrera, J. La hermenéutica contemporánea. Bogotá: Cincel, 1990.

Macía Clavel, Juan. “El arte de la mediación". Lecturas de Paul Ricoeur, Juan Maciá Clavel, Tomás Domingo Moratalla y J. Alberto Ochaíta. Madrid: Universidad Pontificia de Comillas, 1998. 1-65.

Michel, Johann "El animal hermenéutico". Paul Ricoeur. Del hombre falible al hombre capaz, coordinador Fiasse Gaëlle. Buenos Aires: Nueva Visión, 2009.

Platón. “Apología de Sócrates". Diálogos I, Traductor J. Calonge. Madrid: Gredos, 2008. 147-186.

Ricoeur, Paul. Autobiografía intelectual. Traductora Patricia Willson. Buenos Aires: Nueva Visión, 2007.

Ricoeur, Paul. "Autocomprensión e historia". Paul Ricoeur: los caminos de la interpretación. Symposium internacional sobre el pensamiento filosófico de Paul Ricoeur (Granada, 23-27 de noviembre de 1987), ed. Tomás Calvo Martínez y Remedios Ávila Crespo. Barcelona: Anthropos, 1991.

Ricoeur, Paul, Amor y justicia. Traductor Tomás Domingo Moratalla. Madrid: Caparrós Editores,1993.

Ricoeur, Paul. El conflicto de las interpretaciones. Ensayos de hermenéutica. Traductora Alejandrina Falcón. Argentina: Fondo de Cultura Económica, 2003. 
Ricoeur, Paul. Escritos y conferencias: alrededor del psicoanálisis. Traductor Adolfo Castañón. México: Siglo XXI, 2009a.

Ricoeur, Paul. Finitud y culpabilidad. Traducción de Cristina Peretti, Julio Díaz Galán y Carolina Meloni. Madrid: Trotta, 2004.

Ricoeur, Paul. Freud: una interpretación de la cultura. Traductor Armando Suarez. México: Siglo Veintiuno Editores, 2009b.

Ricoeur, Paul. Sí mismo como otro. Traductor Agustín Neira Calvo. México: Siglo XXI, 2006a.

Ricoeur, Paul. Teoría de la interpretación. Discurso y excedente de sentido. Trad. Graciela Monges Nicoalu. México: Universidad Iberoamericana y Siglo XXI, 2006b.

Ricoeur, P. y Changeux, J. P. La naturaleza y la norma. Lo que nos hace pensar. Traductor Carlos Ávila Flores. México: Fondo de Cultura Económica, 2012. 